\title{
KARAKTERISTIK PENERAPAN MEDIA PEMBELAJARAN BILINGUAL PADA PEMBELAJARAN SAINS
}

\author{
Noerdjanah \\ Kementerian Kesehatan Politeknik Kesehatan Surakarta Jurusan Fisioterapi
}

\begin{abstract}
Management, Learning Media, Learning Bilingual. The purposes of this study were to describe the characteristics of the application of bilingual instructional media on learning science. This research is qualitative research that is done at the fields (field research). This research used ethnography research approach characteristics. The source of data is used schools characters and overview of learning science data at SMA Batik 1 of Surakarta in drawn form, interview fieldnote, and schools document achievement. The informant in this research are the principal and teachers at SMA Batik 1 of Surakarta. The data is collected through observation, interview, and documentation. The data as analyze by using data reduction technique, data offered, and data verification/ conclusion taking. The test of data validity used credibility technique, transferability technique, dependability technique and confirmability technique. Conclusions of this research were characteristics of the implementation of bilingual instructional media on the learning of Science subject done through the preparation of learning, implementation of the learning, and evaluation of learning; Handling covers: motivate students, vocab provision to students with English, create a handbook of Science Subject with a bilingual, the use of varied teaching methods and IT-based media, and conduct the program G-SPOT On Line via radio, active students to ask the teacher of Science Subject, as well as to friends who are considered of capable, as well as doing private tutorial at foreign languages.
\end{abstract}

Keywords : Management, Learning Media, Learning Bilingual.

Abstrak : Manajemen, Media Pembelajaran, Pembelajaran Bilingual. Tujuan dari penelitian ini adalah untuk mendeskripsikan karakteristik penerapan media pembelajaran bilingual pada pembelajaran sains. Penelitian ini merupakan penelitian kualitatif yang dilakukan di lapangan (penelitian lapangan). Penelitian ini menggunakan karakteristik pendekatan penelitian etnografi. Sumber data yang digunakan adalah karakter sekolah dan gambaran data pembelajaran sains di SMA Batik 1 Surakarta dalam bentuk gambar, wawancara catatan lapangan, dan prestasi dokumen sekolah. Informan dalam penelitian ini adalah kepala sekolah dan guru di SMA Batik 1 Surakarta. Data dikumpulkan melalui observasi, wawancara, dan dokumentasi. Data tersebut dianalisis dengan menggunakan teknik reduksi data, data yang ditawarkan, dan verifikasi data/ pengambilan kesimpulan. Uji validitas data menggunakan teknik credibility, teknik transferability, teknik dependability dan teknik confirmability. Kesimpulan dari penelitian ini adalah karakteristik implementasi media pembelajaran bilingual pada pembelajaran mata pelajaran Ilmu Pengetahuan yang dilakukan melalui persiapan pembelajaran, implementasi pembelajaran, dan evaluasi pembelajaran; Penanganan meliputi: memotivasi siswa, memberikan vocab kepada siswa dengan 
bahasa Inggris, membuat buku pegangan Subjek Ilmu dengan bilingual, penggunaan metode pengajaran yang bervariasi dan media berbasis IT, dan melakukan program GSPOT On Line via radio, siswa aktif untuk Tanya guru mata pelajaran sains, juga kepada teman yang dianggap mampu, serta melakukan tutorial pribadi berbahasa asing.

Kata Kunci: Manajemen, Media Pembelajaran, Pembelajaran Bilingual.

\section{PENDAHULUAN}

Kemajuan ilmu pengetahuan dan teknologi telah berpengaruh terhadap penggunaan alat-alat bantu mengajar di sekolah-sekolah dan lembaga-lembaga pendidikan lainnya. Bagi sekolah-sekolah yang sudah maju dan mampu, telah menggunakan alat-alat tersebut sebagai alat bantu mengajar, sehingga pembelajaran menjadi lebih efektif dan efisien. Adanya media pembelajaran memerlukan suatu pengelolaan agar dapat terorganisir dengan baik.

Dalam pembelajaran di kelas, sarana/ fasilitas alat yang digunakan untuk memperlancar komunikasi pembelajaran disebut dengan media pembelajaran. Komponen yang terdapat dalam pembelajaran sebagai komunikasi adalah pengajar dapat menjalankan fungsinya sebagai pemberi pesan (komunikator), pembelajar sebagai penerima pesan (komunikan), materi pelajaran sebagai pesan, alat bantu pembelajaran sebagai saluran atau media pembelajaran adalah umpan balik yang manifestasinya berupa pertanyaan, jawaban dan persilangan pendapat, baik dari pembelajar maupun dari pengajar.

Proses komunikasi dan komunikan tidak terlepas dari bahasa sebagai sumber penyampaian pesan. Pemakaian ragam bahasa perlu penyesuaian antara situasi dan fungsi pemakaian.

Pembelajaran bilingual merupakan bentuk pembelajaran dengan menggunakan dua bahasa berbeda.
Pembelajaran bilingual dimaksudkan untuk membantu peserta didik mempelajari materi pelajaran yang tersedia dalam bahasa Inggris bagi siswa yang sehari-hari menggunakan Bahasa Indonesia.

Saat ini SMA Batik 1 Surakarta, merupakan salah satu sekolah rintisan standart Internasional. Status RSBI di SMA Batik 1 Surakarta tentu memerlukan kelengkapan sarana dan prasarana yang memadai sehingga dapat memberikan pelayanan pembelajaran yang terbaik, diantaranya adalah media pembelajaran.

SMA Batik 1 Surakarta saat ini sedang mengembangkan kegiatan pembelajaran untuk kelas sains (biologi, fisika, kimia dan matematika) dengan model bilingual yang dilaksanakan sejak tahun 2009. Motivasi SMA Batik 1 menyelenggarakan pembelajaran dengan bilingual adalah untuk meningkatkan kualitas pembelajaran berdasarkan ISO 9001.

\begin{tabular}{lccr}
\multicolumn{2}{c}{ Permasalahan } & yang muncul \\
kemudian & adalah & \multicolumn{2}{c}{ bagaimanakah } \\
kelengkapan & sarana & prasarana media
\end{tabular} dalam pembelajaran bilingual yang digunakan SMA Batik 1 Surakarta. Pembelajaran bilingual ini memerlukan sarana dan prasarana yang lebih banyak daripada pembelajaran dengan satu bahasa saja. Sarana prasarana bilingual dalam bahasa Indonesia misalnya memerlukan laboratorium bahasa, kurikulum yang sesuai dan kompetensi guru. Pada kompetensi gurupun, proses pembelajaran 
bilingual menuntut guru agar dapat melakukan kegiatan pembelajaran dengan dua bahasa.

Berdasarkan beberapa permasalahan dalam penelitian di atas, penulis merancang judul "Pengelolaan Media Pembelajaran Bilingual (Studi Situs di SMA Batik 1 Surakarta) ", dan focus penelitian ini adalah " Bagaimanakah karakteristik penerapan media pembelajaran bilingual pada pembelajaran sains di SMA Batik 1 Surakarta? Tujuannya adalah mengetahui karakteristik penerapan media pembelajaran bilingual pada pembelajaran sains di SMA Batik 1 Surakarta.

\section{METODE PENELITIAN}

Jenis penelitian ini adalah penelitian kualitatif yang dilaksanakan di lapangan (field research). Pendekatan yang digunakan dalam penelitian ini adalah pendekatan etnografi.

Penelitian ini dilakukan di SMA Batik 1 Surakarta. Alasan penelitian ini adalah bahwa SMA Batik 1 merupakan salah satu SMA swasta yang paling awal menyelenggarakan pendidikan bilingual di kota Surakarta. SMA Batik 1 memiliki keberanian lebih, meskipun SMA tersebut berada dalam yayasan swasta, yakni menyelenggarakan pembelajaran bilingual. Peneliti dalam penelitian ini menempatkan diri sebagai pengamat. Penetapan peneliti dalam kehadiran penelitian sebagai pengamat karena peneliti belum mengetahui atau tidak mengenal situasi dan kondisi lokasi penelitian tersebut.

Sumber data yang digunakan berupa data hasil wawancara, observasi, dan dokumentasi dari kepala sekolah, guru dan siswa dalam bentuk gambar, fieldnote wawancara, serta arsip dokumentasi sekolah. Informan dalam penelitian ini adalah kepala sekolah dan guru SMA Batik 1 Surakarta.

Data dikumpulkan melalui teknik wawancara, observasi, dan dokumentasi. Data dianalisis dengan menggunakan teknik reduksi data, sajian data, dan verifikasi data/penarikan kesimpulan. Dalam menguji keabsahan data digunakan teknik kredibilitas (Credibility), teknik transferabilitas (transferability), teknik dependabilitas (dependability) dan teknik konfirmabilitas (confirmability).

\section{HASIL PENELITIAN \\ Karakteristik Penerapan Media Pembelajaran Bilingual Pada Pembelajaran Pendidikan Sains}

Rintisan Sekolah Bertaraf

Internasional merupakan salah satu upaya dari pemerintah untuk meningkatkan kualitas pendidikan di Indonesia. Dan berpotensi untuk melaksanakan proses layanan pendidikan yang berkualitas untuk menghasilkan lulusan yang memiliki potensi dan prestasi berdaya saing secara nasional maupun Internasional.

Proses pembelajaran di Rintisan Sekolah Bertaraf Internasional harus interaktif, inspiratif, menyenangkan, dan menantang sehingga dapat memotivasi siswa untuk berpartisipasi aktif dalam pembelajaran serta memberikan ruang yang cukup untuk peserta didik agar memiliki akhlak mulia, budi pekerti luhur, kepribadian unggul, kepemimpinan, jiwa entrepreneurship, jiwa patriot, jiwa inovator, prakarsa, kreativitas, kemandirian berdasarkan bakat, minat dan perkembangan fisik maupun psikologisnya secara optimal.

Proses pembelajaran diperkaya dengan model pembelajaran sekolah unggul, seperti penerapan standar belajar, 
standar mengajar: persiapan pembelajaran, pemilihan bahan ajar, strategi pembelajaran, pengelolaan kelas, pemilihan alat peraga pembelajaran, dan pemilihan sumber belajar. Proses pembelajaran diperkaya pula dengan menerapkan pembelajaran berbasis TIK pada semua mata pelajaran, menggunakan Bahasa Inggris untuk kelompok sains dan matematika. Pembelajaran mata pelajaran lainnya kecuali bahasa asing, menggunakan Bahasa Indonesia.

Berawal dari Rintisan Sekolah Bertaraf Internasional, maka di SMA Batik I Surakarta kelas X telah dilaksanakan pembelajaran Pendidikan Sains dengan menggunakan bilingual. Dalam konsep pembelajaran di RSBI/ SBI, Pembelajaran dengan dua bahasa (bilingual) yaitu Bahasa Indonesia dan Bahasa Inggris diperlukan agar siswa mampu menguasai bahasa internasional. Pembelajaran Pendidikan Sains ini, bukanlah suatu kewajiban yang harus diterapkan baik guru maupun siswa kelas $X$. Namun, ini merupakan sebuah kebijakan dari Kepala Sekolah, guru Pendidikan Sains untuk membiasakan, dan memberikan pengajaran dengan menggunakan bilingual Bahasa Inggris, agar siswa terbiasa dan mampu memahami segala sesuatunya dengan menggunakan bilingual. Misalnya, jika pembelajaran Pendidikan Sains dengan menggunakan Bahasa Inggris, siswa dapat memahami materi pelajaran yang berasal dari buku berBahasa Inggris. Sumber-sumber yang berBahasa Inggris tersebut, tidaklah langsung diberikan kepada siswa. Akan tetapi, siswa diberikan potongan-potongan kata dengan arti Bahasa Inggris atau vocab. Sehingga, jika siswa kurang faham terhadap Bahasa Inggris, maka dia akan mencoba untuk memahaminya dengan menggunakan Bahasa Inggris. Disini, Guru Pendidikan Sains mengupayakan pembelajaran dengan menggunakan bilingual melalui pembiasaan dan praktik dalam pembelajaran. Dengan cara mengajarkan Membaca, mendengarkan, berbicara, menulis dengan Bahasa Inggris maupun Bahasa Inggris bertemakan Pendidikan Sains.

Pembelajaran Pendidikan Sains dengan menggunakan bilingual ini adalah tahap awal dari Rintisan Sekolah Bertaraf Internasional SMA Batik I Surakarta. Yang akan dievaluasi dan akan dilakukan perbaikan-perbaikan dalam pembelajaran bila terdapat kekurangan didalamnya. Pada kenyataannya, setelah dilakukan pembelajaran dan dievaluasi, terbukti bahwa mayoritas siswa kelas X SMA Batik I Surakarta sudah bisa memenuhi KKM yang telah ditentukan. Yaitu dengan nilai KKM 75. Sehingga, baik pihak sekolah, maupun Guru Pendidikan Sains sendiri masih tetap optimis untuk menggunakan bilingual dalam pembelajaran.

\section{PEMBAHASAN}

Pembelajaran Pendidikan Sains dengan menggunakan bilingual diperkaya pula dengan menerapkan pembelajaran berbasis TIK. Sehingga, diharapkan pembelajaran akan berjalan dengan efektif, efisien, menyenangkan, dan memotivasi. Tahapan-tahapan dalam pembelajaran diantaranya:

a. Tahap perencanaan

Perencanaan Pembelajaran yaitu suatu cara atau upaya yang memuaskan untuk membuat kegiatan dapat berjalan dengan baik, sebagai langkah antisipasi dalam kegiatan memilih, menetapkan, mengembangkan metoda 
pembelajaran, mengorgasisasikan pembelajaran, menyampaikan isi pembelajaran, dan menata interaksi sumber belajar sehingga kegiatan tersebut mencapai tujuan yang telah ditetapkan.

Secara umum, perencanaan proses pembelajaran meliputi silabus dan rencana pelaksanaan pembelajaran (RPP) yang memuat sekurangkurangnya tujuan pembelajaran, materi ajar, metode pembelajaran, sumber belajar dan penilaian hasil belajar.

\section{Rencana}

Pelaksanaan

Pembelajaran (RPP) adalah rencana yang menggambarkan prosedur dan manajemen pembelajaran untuk mencapai satu atau lebih kompetensi dasar yang ditetapkan dalam Standar Isi dan dijabarkan dalam silabus.

Silabus adalah rencana pembelajaran pada suatu kelompok mata pelajaran dengan tema tertentu, yang mencakup standar kompetensi, kompetansi dasar, materi pembelajaran, indikator, penilaian, alokasi waktu dan sumber belajar yang dikembangkan oleh setiap satuan pendidikan.

Dengan demikian, sebagai seorang pendidik (guru), sebaiknya merencanakan pembelajaran dengan baik dan efektif. Dengan harapan, agar pada saat pelaksanaan pembelajaran, bisa berjalan dengan lancar.

Berdasarkan hasil observasi yang peneliti temukan di lapangan, Bahwasanya Guru Pendidikan Sains telah melaksanakan persiapan sebelum pembelajaran berlangsung, Meliputi Rencana Pelaksanaan Pembelajaran (RPP), dan Silabus. Perencanaan ini, juga meliputi pembelajaran Pendidikan Sains dengan menggunakan bilingual.
Dengan mempersiapkan instrumeninstrumen pembelajaran berBahasa Inggris yang bertujuan, untuk mempermudah siswa dalam menerima pelajaran. Misalnya, Guru Pendidikan Sains mempersiapkan vocab, memberikan contoh-contoh tentang materi yang akan diajarkan dengan menggunakan bilingual. Yang kemudian, akan didukung dengan buku pedoman Pendidikan Sains untuk siswa yang sudah dipersiapkan oleh guru sebelumnya.

Dapat dikatakan bahwa, Guru Pendidikan Sains sebagai pelaksana dalam pembelajaran, juga sebagai fasilitator dan motivator. Dengan persiapan yang telah dilakukan, Guru Pendidikan Sains tetap optimis dalam melaksanakan pembelajaran Pendidikan Sains dengan menggunakan bilingual. dan berharap agar kemampuan siswa semakin meningkat dalam hal Bahasa Inggris serta mampu memahami, dan menghayati isi/materi Pendidikan Sains yang telah diajarkan dengan baik dan benar.

b. Tahap pelaksanaan.

Tahap ini merupakan tahap implementasi atau tahap penerapan atas desain perencanaan yang telah dibuat guru. Hakikat dari tahap pelaksanaan adalah kegiatan operasional pembelajaran itu sendiri. Dalam tahap ini, guru melakukan interaksi belajar mengajar melalui penerapan berbagai strategi, metode, dan teknik pembelajaran, serta pemanfaatan media.

$$
\text { Dalam pelaksanaan }
$$

pembelajaran Pendidikan Sains dengan menggunakan bilingual, Guru Pendidikan Sains telah melaksanakan 
pembelajaran tersebut sesuai dengan perencanaan yang telah dibuat sebelumnya. Sehingga, dalam pelaksanaan pembelajaran, bisa berjalan sesuai dengan rancangan dan berjalan dengan baik.

Guru Pendidikan Sains
menggunakan media IT dalam pembelajaran dengan beberapa metode yang variatif. Misalnya, Diskusi, ceramah. Sehingga, dalam penerapan pembelajaran Pendidikan Sains dengan menggunakan bilingual, siswa termotivasi dan antusias untuk mengikutinya.

c. Tahap evaluasi

Evaluasi merupakan proses penaksiran terhadap kemajuan, pertumbuhan, dan perkembangan peserta didik untuk tujuan pendidikan. Evaluasi Pendidikan Sains adalah suatu kegiatan untuk menentukan taraf kemajuan suatu aktivitas didalam pendidikan Sains. Program evaluasi ini diterapkan dalam rangka mengetahui tingkat keberhasilan seorang pendidik dalam menyampaikan materi pelajaran, menemukan kelemahankelemahan yang dilakukan, baik berkaitan dengan materi, metode, fasilitas, dan sebagainya.

$\begin{array}{cr}\text { Evaluasi } & \text { Pembelajaran } \\ \text { Pendidikan } & \text { Sains }\end{array}$ menggunakan bilingual di SMA Batik I Surakarta meliputi ulangan harian, ulangan semester, dan remidi. Evaluasi ini dilakukan oleh siswa dengan pemantauan Guru Pendidikan Sains. Apakah siswa mampu mengerti dan memahami tentang materi yang telah diberikan guru menggunakan bilingual atau tidak.

Hasil evaluasi siswa kelas $\mathrm{X}$ SMA Batik I Surakarta yang dilakukan melalui ulangan harian, ulangan semester, menunjukkan bahwa mayoritas siswa mampu memahami dan mengerti tentang materi Pendidikan Sains yang telah disampaikan oleh guru atau lulus dengan mencapai nilai KKM yang ditentukan. KKM yang telah ditentukan adalah 75. Namun, dari hasil evaluasi ini ditemukan beberapa siswa yang mempunyai nilai dibawah KKM yang telah ditentukan. Sehingga, Guru Pendidikan Sains mengadakan remidi untuk memperbaiki nilai siswa agar dapat mencapai KKM yang telah ditentukan.

Dari serangkaian perencanaan, pelaksanaan, dan evaluasi pembelajaran Pendidikan Sains dengan menggunakan bilingual yang dilakukan oleh Guru Pendidikan Sains, merupakan upaya untuk meningkatkan kualitas dan kuantitas belajar siswa serta untuk mewujudkan kader-kader yang berwawasan global, kreatif, inovatif dan berakhlaqul karimah. Manajemen yang dilakukan oleh SMA Batik I Surakarta tersebut juga merupakan suatu proses pelaksanaan sistem manajemen mutu sesuai standart ISO 9001: 2008, yang kedepannya diharapkan dapat berpengaruh secara signifikan terhadap peningkatan kualitas pendidikan, khususnya di SMA Batik I Surakarta.

Hal ini sejalan dengan apa yang disampaikan oleh J. Michalska-Ćwiek (2009) dalam penelitiannya yang berjudul The Quality Management System in Education - Implementation and Certification. Ćwiek menyatakan bahwa kesadaran tentang semua unsur yang terkait dengan kualitas memberikan dampak penting pada 
sistem manajemen mutu dalam pendidikan. Hal ini dapat dinyatakan bahwa kualitas dalam pendidikan terutama dalam proses pembelajarannya tidak terlepas dari peran semua unsur yang terlibat didalamnya. Begitu juga dengan penerapan media pembelajaran bilingual pada Pendidikan Sains di SMA Batik I Surakarta.

\section{KESIMPULAN DAN SARAN}

Diharapkan dengan program ini siswa mampu aktif dalam penggunaan bilingual terkait dengan pembelajaran Pendidikan Sains. Solusi yang dilakukan siswa untuk mengatasi kendala dalam pembelajaran Pendidikan Sains dengan menggunakan bilingual diantaranya adalah: bertanya langsung kepada Guru Pendidikan Sains terkait hal yang kurang dipahami, terutama Bahasa Inggris. Diskusi dengan teman yang dianggap mampu dalam Bahasa Inggris dan ada pula yang les privat Bahasa asing untuk lebih memahami pembelajaran Pendidikan Sains dengan menggunakan bilingual. Namun, yang melakukan les privat hanya beberapa orang saja. Disini, siswa cukup terbantu dengan adanya buku panduan dengan menggunakan bilingual. Sehingga, siswa bisa belajar terlebih dahulu sebelum pembelajaran dimulai.

$$
\text { Mengacu pada penelitian }
$$

M.R.Osman, et.all, (2004) dengan judul Internal Customer Satisfaction in ISO 9001 Certified Manufacturing Companies, selain penanganan terhadap kendala pembelajaran bilingual, pengelolaan media pembelajaran bilingual pada Pembelajaran Sains dapat juga didukung dengan meningkatkan keterlibatan dan komunikasi manajemen sehingga dapat meningkatkan tingkat kepuasan pelanggan internal, dalam hal ini adalah siswa sebagai subjek pembelajaran bilingual. Ini diikuti dengan tanggung jawab manajemen, pemantauan kepuasan pelanggan internal, motivasi dan reward dan proses kontrol.

Karakteristik penerapan media pembelajaran bilingual pada pembelajaran Pendidikan Sains adalah guru melaksanakan pembelajaran Pendidikan Sains dengan cara memotivasi siswa dan menggunakan metode pembelajaran yang variatif dan berbasis IT, sehingga dalam penggunaan bilingual pada pembelajaran Pendidikan Sains tidak menjenuhkan. Buku pelajaran Pendidikan Sains juga menggunakan bilingual, demikian juga dengan RPP yang disusun oleh guru Pendidikan Sains sudah menggunakan bilingual.

Pengelolaan media pembelajaran bilingual pada pembelajaran sains adalah penanganan kendala-kendala yang terjadi dalam penggunaan bilingual dalam pembelajaran Pendidikan Sains di kelas X RSBI SMA Batik I Surakarta. Penganganan yang digunakan oleh guru antara lain: memotivasi siswa dan melakukan pemberian vocab kepada siswa dengan Bahasa Inggris, membuat buku pedoman Pendidikan Sains dengan bilingual yang berisikan materi pembelajaran Pendidikan Sains dengan Bahasa Inggris, penggunaan metode pembelajaran yang variatif dan media berbasis IT, serta melakukan program GSPOT On Line melalui radio. Kemudian, penanganan yang digunakan siswa adalah dengan bertanya langsung kepada Guru Pendidikan Sains, bertanya kepada teman yang dianggap mampu dalam hal tersebut, serta melakukan les privat Bahasa asing untuk dapat memahami pembelajaran dengan menggunakan bilingual. 
1. Bagi sekolah, khususnya bagi para guru yang belum menerapkan bilingual dalam pembelajarannya, sebaiknya menggunakan bilingual. Karena, hal ini merupakan wujud pembiasaan bagi siswa dalam memahami pembelajaran. Disamping itu, untuk pengembangan sekolah selanjutnya, yaitu dari tahap RSBI menuju SBI. Sehingga, dari waktu ke waktu siswa akan berkembang dan akan siap dalam menghadapi era globalisasi.

2. Dalam pengembangan sekolah menuju Sekolah Bertaraf Internasional (SBI), khususnya dalam proses pembelajaran dengan menggunakan bilingual, sebaiknya memperhatikan beberapa hal, diantaranya:

a. Substansi pelajaran harus cocok dengan tingkat perkembangan kognitif dan kemampuan Bahasa Inggris siswa.

b. Sekolah harus dapat menciptakan lingkungan belajar yang kondusif untuk mendorong pemakaian Bahasa yang bermakna baik tulis maupun lisan.

c. Pembelajaran harus menekankan latihan pemecahan masalah dan siswa didorong untuk bekerjasama melalui tema-tema yang menarik dan menantang.

\section{DAFTAR RUJUKAN}

Arikunto, Suharsimi. 2006. Prosedur Penelitian Suatu Pendekatan Praktik. Edisi Revisi VI. Jakarta: PT. Rineka Cipta.

Dardjowidjojo, $\quad$ Soenjono. 2005. Psikolinguistik Pengantar Pemahaman Bahasa Manusia. Jakarta: Yayasan Obor Indonesia.

Dewi Lili Amiyati, Andi Mariono, 2010, Pengembangan

Media
Pembelajaran pada Mata Pelajaran Bahasa Daerah Pokok Bahasan Aksara Jawa Kelas VII Di SMP Negeri 2 Sidoarjo.

Fattah, Nanang. 2004. Landasan Manajemen Pendidikan. Bandung: PT. Remaja Rosdakarya.

Hamalik, Oemar. 2007. Manajemen Pengembangan Kurikulum. Bandung: PT. Remaja Rosdakarya.

Milles, Matthew B. and Michael Huberman. 2005. Analisis Data Kualitatif. Jakarta: UI Press.

Moleong J. Lexy. 2007. Metodologi Penelitian Kualitatif. Bandung: PT. Remaja Rosdakarya.

Sanaky, Hujair. 2009. Media Pembelajaran. Yogyakarta: Safiria Insania Press.

Siti Azizah, 2010. Bilingualism and Its Implications For Language Teaching and Learning.

Spradley P. James, Marzali Amri. 2007. Metode Etnografi. Yogyakarta : Tiara Wacana.

Sudrajat, Ahmad. 2008. Media Pembelajaran. Diakses dari: http://akhmadsudrajat.wordpress.c om/2008/01/12/konsep-mediapembelajaran/

Sukardi, 2006. Penelitian Kualitatif Naturalistik dalam Penelitian. Yogyakarta: Usaha Keluarga.

Syamsudin \& Damaianti, Vismaia. 2007. Metode Penelitian Pendidikan Bahasa. Bandung: PT. Remaja Rosdakarya.

Thomas Wibowo Agung Sutjiono, 2005. Pendayagunaan Media Pembelajaran, Jurnal Pendidikan Penabur - No.04 / Th.IV / Juli 2005. 